\title{
Serum Antibodies to the Catalase Antigen of Aspergillus fumigatus in Cattle
}

Aspergillus fumigatus is an important agent of mycotic infection in cattle and a potent source of antigens. However, the efficacy of serological diagnosis of aspergillosis in cattle remains controversial. Corbel (1972) and Knudtson et al. (1974) considered a precipitin assay useful as a supplementary test in the diagnosis of mycotic abortion, whereas Wiseman et al. (1984) found the specificity too low to justify its routine use. We have studied 1) the antibody response to the catalase antigen of $\mathrm{A}$. fumigatus in experimentally infected cattle and 2) the prevalence of catalase antibodies and $\mathrm{A}$. fumigatus precipitins in healthy and diseased cattle. The aim was to ascertain how far detection of antibodies to a defined fungal antigen can contribute to the often difficult diagnosis of mycosis.

Four Jersey bull calves (weight 50-60 kg) and one artificially inseminated cow were inoculated intravenously with freshly harvested A. fumigatus conidii, $10^{3}$ to $10^{8}$ colony forming units per injection as detailed below. Conidii were suspended in sterile $0.9 \%$ saline with $0.01 \%$ Tween 80 . Venous blood samples were obtained twice a week for up to 21 weeks, and animals were sacrificed at the end of experiments. Mycological cultures and histopathological examination were performed. Venous blood samples from healthy cattle $(n=98)$ were obtained from a herd and slaughterhouse cattle. Seventeen diseased cattle admitted to the Department of Internal Medicine at the Royal Veterinary and Agricultural University were also investigated serologically.
Sera were stored at $-20^{\circ} \mathrm{C}$ until analysis. Precipitating antibodies to the catalase antigen of A. fumigatus were detected by an immunoelectrophoretic technique as previously described (Schønheyder et al. 1985). Immunoprecipitated catalase in the dried gel was visualized by addition of hydrogen peroxide, whereby a characteristic »bubble« reaction was seen. A hyperimmune rabbit serum was included as a positive control in each run. Precipitating antibodies to A. fumigatus were detected by double immunodiffusion (ID) as previously described (Schønheyder et al. 1982). Positive sera were tested in two-fold serial dilutions in both assays in order to determine end-point titres.

In none of the 5 experimental animals serum antibodies to $\mathbf{A}$. fumigatus were detected prior to inoculation. A dose of $10^{3}$ conidii was well tolerated in 2 calves and no antibody response occurred within 2 weeks. A second dose of $10^{7}$ conidii on day 14 was also well tolerated, and only one of the calves developed catalase antibodies and precipitins (titres $=1$ ) within 4 weeks. A third inoculation of this calf with $10^{8}$ conidii (day 51) boosted titres to 4 and 16 , respectively, and when sacrificed on day 70 hyphae and a granulomatous reaction was seen in the kidneys. A third inoculation of the other calf (day 137) elicited a weak precipitin response within 2 weeks, but no catalase antibodies were detected. When sacrificed on day 151 no evidence of mycosis was found.

Two additional calves were inoculated primarily with $10^{8}$ conidii. Precipitins developed within 2 and 3 weeks, respectively, in ti- 
tres up to 8, but no catalase antibodies were found. At autopsy on days 23 and 28, respectively, aspergillosis was confirmed mycologically and histopathologically in both animals. The pregnant cow was inoculated with $10^{8}$ conidii on day 158 of gestation and precipitins became detectable on day 164 . A plateau titre of 4 was maintained for a month, when abortion occurred on day 202 . A. fumigatus was cultured from the placenta and foetus, and histologically necrotizing placentitis and hyphae were revealed. Catalase antibodies were not revealed in any of the serum samples.

None of 98 healthy cattle had a positive catalase antibody test, whereas 15 had A. fumigatus precipitins in titres 1 or 2 . Of the 17 cattle admitted to the university clinic 6 $(35 \%)$ had precipitins, but only one cow with a precipitin titre of 4 reacted for catalase antibodies (titre $=1$ ). This cow was acutely ill with extensive decubital ulcers, but no aetiological diagnosis was obtained. In 2 cattle a postmortem diagnosis of acute mycosis was inferred from histopathological study, but neither A. fumigatus precipitins nor catalase antibodies had been found.

This investigation has confirmed a high prevalence of $\mathrm{A}$. fumigatus precipitins in both healthy and diseased cattle (Wiseman et al. 1984). Spontaneous occurrence of catalase antibodies was recorded in only one cow, that might have had an occasional aspergillus infection. However, catalase antibodies developed in only 1 of 5 experimentally infected cattle, and thus the catalase antibody test appears not to be applicable to the serological diagnosis of aspergillosis in cattle. It is noteworthy that cattle with A. fumigatus infection (inoculum $\approx 10^{8}$ conidii) mounts a conspicious precipitin reaction within 2 to 3 weeks, and longitudinal serological survey by this technique and e.g. immunoblotting might contribute to the diagnosis of mycotic abortion and other forms of aspergillosis in cattle.

\section{H. Schønheyder}

Institute of Medical Microbiology, University of Aarhus, Denmark.

\section{H. E. Jensen}

Department of Veterinary Pathology, Royal Veterinary and Agricultural University, Frederiksberg, Denmark.

\section{References}

Corbel M J: The serological response to Aspergillus fumigatus antigens in bovine mycotic abortion. Brit Vet. J. 1972, 128, lxxiii-lxxv.

Knudtson $W U$, Kirkbride $C A$, Thurston J R: Bovine mycotic abortion: serology as an aid in diagnosis. Proceedings of the American Association of Veterinary Laboratory Diagnosticians, $17^{\text {th }}$ Annual Meeting, October 1974, 299-303.

Schønheyder H, Andersen P, Munck Petersen J C: Rapid immunoelectrophoretic assay for detection of serum antibodies to Aspergillus fumigatus catalase in patients with pulmonary aspergillosis. Eur. J. Clin. Microbiol. 1985, 4, 299-303.

Schønheyder H, Andersen P, Stenderup A: Serum antibodies to Aspergillus fumigatus in patients with pulmonary aspergillosis detected by immunofluorescence. Acta Pathol. Microbiol. Immunol. Scand. Sect. B 1982, 90, 273-279.

Wiseman A, Dawson CO, Selman IE: The prevalence of serum precipitating antibody to Aspergillus fumigatus in adult cattle in Britain. J. Comp. Pathol. 1984, 94, 535-552.

(Received March 21, 1988).

Reprints may be requested from: Henrik Schønheyder, Institute of Medical Microbiology, Bartholin Building, University of Aarhus, DK-8000 C, Denmark. 